\title{
O princípio de prática situada na aprendizagem da literacia: a perspectiva dos alunos'
}

Íris Susana Pires Pereira"

I- Este estudo foi realizado no âmbito de uma licença sabática da autora, subvencionada pela Fundação para a Ciência e Tecnologia (SFRH/ $\mathrm{BSAB} / 1440 / 2014)$.

II- Universidade do Minho, Braga, Portugal.

Contato: iris@ie.uminho.pt

\section{Resumo}

0 artigo resulta de uma investigação realizada no âmbito de uma iniciativa governamental destinada a melhorar os níveis de literacia nas séries iniciais do ensino fundamental em Portugal. A investigadora estudou as representações dos alunos sobre essa experiência por meio da realização de entrevistas em grupo. Este artigo analisa os dados referentes às representações dos alunos sobre uma das dimensões pedagógicas centrais da aprendizagem da literacia, nomeadamente a constituída pela prática situada. A análise qualitativa revela representações muito positivas sobre a prática que situou a aprendizagem, tendo os alunos expressado opiniões e sentimentos extremamente favoráveis sobre a prática de aprendizagem de literacia que experimentaram. A análise dos dados desvelou ainda que o contexto que situou a aprendizagem foi ativo, lúdico, colaborativo e mediado pelas TIC. Esses resultados fundamentam, do ponto de vista único dos próprios aprendentes, uma redefinição do entendimento atual do princípio da prática situada da literacia nas séries iniciais do ensino fundamental, no sentido do reconhecimento da centralidade da ludicidade nessa aprendizagem.

\section{Palavras-chave}

Literacia - Pedagogia - Prática situada - Entrevista em grupo - Ludicidade. 


\title{
The principle of situated practice in literacy learning: students' perspectives'
}

Íris Susana Pires Pereira"

\begin{abstract}
This article derives from research developed in the context of the implementation of a governmental initiative aimed to enhance literacy learning in primary education in Portugal. The researcher studied students' representations about their learning experience through group interviews. This article focuses on data concerning students' representations about one of the central pedagogical dimensions of literacy learning, namely situated practice. Qualitative analysis revealed students' very positive representations about the practice which situated their learning, as they expressed extremely favourable opinions and feelings. Data analysis further unveiled that the context of learning was active, playful, collaborative, and mediated by ICT. Such results provide foundations for a theoretical redefinition of current conceptions of situated practice by evidencing the centrality of playfulness as learning practice in the education of the first grades of primary education. This is an original contribution made from the perspectives of learners themselves.
\end{abstract}

\section{Keywords}

Literacy - Pedagogy - Situated practice - Froup interview - Playfulness.

I- This research was carried out during a researchers' sabbatical period, which was supported by Fundação para a Ciência e Tecnologia (SFRH/BSAB/1440/2014).

II- Universidade do Minho, Braga, Portugal.

Contact: iris@ie.uminho.pt 
Entre 2006 e 2010, o Ministério da Educação Português implementou o Programa Nacional de Ensino do Português (PNEP) com a finalidade de melhorar as "condições de ensino e aprendizagem da língua portuguesa como meio de melhorar os níveis de compreensão de leitura e de expressão oral e escrita em todas as escolas do 1. ciclo" (Despacho n. ${ }^{\circ}$ 546/2007, Diário

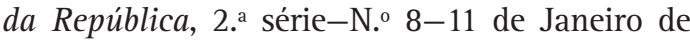
2007, p. 899). 0 governo justificou a necessidade desta intervenção face aos baixos resultados em literacia das crianças desse período escolar (correspondente à classe de alfabetização e às três primeiras séries do ensino fundamental no Brasil) nas provas nacionais de aferição realizadas no final do ciclo entre 2000 e 2005, mas também nos exames nacionais do 9. ano de 2005 e em estudos internacionais dos quais Portugal até então tinha participado (Reading Literacy - IEA, 1992; Pisa, 2000 e 2003).

0 PNEP se assumiu como uma formação contínua de professores e se sustentou no pressuposto de que "o desenvolvimento profissional dos professores afeta o desempenho de aprendizagem dos alunos num processo em cadeia” (SIM-SIM, 2011, p.13). A implementação do PNEP envolveu professores-formandos, professores-formadores e núcleos de coordenação sediados em instituições de ensino superior com responsabilidades na formação de professores de primeiro ciclo. 0 ministério preparou um currículo de conteúdos relativos ao ensino de português, que os professores estudaram, com a mediação e supervisão dos formadores, nos seus contextos de prática, sobre os quais intervieram intencionalmente durante pelo menos um ano letivo, com o fim de assim melhorarem os resultados dos alunos e, desse modo, edificarem conscientemente o seu desenvolvimento profissional (DAY, 2001; KEMMIS; MCTAGGART, 1987; LATORRE, 2003). Nesse processo, às instituições de ensino superior coube a formação de formadores, bem assim como a mediação da implementação do plano centralmente desenhado e a monitorização da consecução do processo formativo realizado nos agrupamentos de escolas
(PEREIRA，2010a; PEREIRA，2010b; PEREIRA; BRAGA; RIAÑO, 2015).

Além de pretender melhorar os níveis de literacia dos alunos, o governo teve também por objetivo "estimular nas instituições de ensino superior a produção de investigação no ensino da língua na faixa etária visada" (Comissão Nacional De Coordenação e Acompanhamento do PNEP - CNA, 2006, p. 3). Esse programa constituiu-se, portanto, como uma oportunidade excepcional de experimentar e investigar um determinado entendimento da educação em literacia no ensino fundamental. Este artigo resulta da coordenação e investigação realizadas no núcleo sediado na Universidade do Minho, de que fui responsável entre 2008 e 2010.

Durante esse período, o meu principal objetivo consistiu em apoiar os professores formadores e, por meio da sua mediação, os formandos no desenvolvimento de um sentido de visão (DAY, 2001) sobre as complexidades da educação em literacia no primeiro ciclo apoiado no plano de conteúdos centralmente definido. Nesse âmbito, uma das minhas principais preocupações consistiu na exploração sistemática de um entendimento da pedagogia da literacia, cujo estudo iniciara com a realização do meu doutorado (PEREIRA, 2008), entendimento esse amplamente sustentado por perspectivas socioculturais, de inspiração vygotskiana.

No final do programa, iniciei um estudo para conhecer as representações dos alunos sobre a sua experiência de aprendizagem. Este artigo resulta desse estudo, centrando-se num dos princípios sobre os quais se edificou a pedagogia da literacia, nomeadamente o constituído pela prática situada. A minha principal finalidade com este texto é a de contribuir para a discussão teórica desse princípio no primeiro ciclo do ensino básico.

\section{Enquadramento teórico}

Vygotsky (1995) concebeu a linguagem como um instrumento de mediação fundamental na configuração da cognição 
humana (WERTSCH, 1991). Esse entendimento teve repercussões no entendimento da língua como objeto de aprendizagem escolar, assim como na concepção da finalidade e do processo da sua aprendizagem. No contexto desse entendimento, aprender língua na escola é mais do que uma aprendizagem qualquer. Halliday assevera que "When children learn language (...) they are learning the foundation of learning itself" (HALLIDAY, 1993, p. 93). Na escola, pretende-se justamente que os alunos desenvolvam formas de linguagem que os capacitem cognitivamente para participar de inúmeras situações mediadas pela linguagem que constituem a vida da sua comunidade, nas quais aprendem e se integram socialmente.

Assume-se atualmente que as formas de linguagem que representam o conhecimento cultural que se transmite na escola (linguagem especializada ou da escola) são diferentes das usadas para representar o conhecimento do dia a dia (PEREIRA, 2010b, 2014; GEE, 2001, 2004, 2007, 2010; HALLIDAY, 1993; SCHLEPPEGRELL, 2004). 0 conjunto de práticas de construção de significado que faz uso da linguagem especializada nas múltiplas situações sociais de ação linguística humana é atualmente designado de literacia (GEE, 2007, 2010).

Os estudos socioculturais têm chamado a atenção para o fato de que, na escola, o objeto da aprendizagem é, consequentemente, também ele de natureza cultural. Código escrito, texto e gramática ilustram as categorias básicas do objeto de aprendizagem que essa linguagem especializada assume já a partir dos anos iniciais do ensino fundamental (PEREIRA, 2014; VYGOTSKY, 1995).

Uma das conceitualizações recentes da pedagogia da literacia, desenvolvidas no âmbito dos New Literacy Studies (GEE, 2010), estabelece que a aprendizagem da literacia deve ser regida pela operatividade de quatro princípios básicos: princípio da prática situada, da aprendizagem explícita (das linguagens especializadas), do enquadramento crítico e da prática situada transformada (COPE; KALANTZIS, 2009, 2010; THE NEW LONDON GROUP, 2000).
0 princípio de prática situada, em que me centrarei neste artigo, estabelece fundamentalmente que é a ação linguística com a linguagem especializada que contextualiza a sua aprendizagem (explícita e transformada). De acordo com esse princípio, a linguagem especializada é tacitamente aprendida quando "married closely to specific and connected actions" (GEE, 2010, p. 183), no âmbito das quais se constroem significados de interesse para quem aprende, ainda que meramente simulados na sala de aula. 0 próprio Vygotsky se referiu à dimensão situada da aprendizagem da literacia ao argumentar que

\begin{abstract}
A escrita deverá ser "importante para a vida" [...] possuir um significado para as crianças, deveria despertar nelas uma inquietude intrínseca e ser incorporada numa tarefa importante e básica para a vida. Só então podemos estar certos de que se desenvolverá [...] como uma forma de linguagem realmente nova e complexa (VYGOTSKY, 1979, p. 176177, tradução minha).
\end{abstract}

Uma condição para a aprendizagem situada da literacia é a de que a prática e o diálogo instrucional que enquadra a explicitação dos conteúdos linguísticos construam ativamente uma zona de desenvolvimento próximo para quem aprende. Quando afirma que "a única forma de instrução que se pode considerar boa é a que vai adiante do desenvolvimento e o dirige" (VYGOTSKY, 1995, p. 181, tradução minha), Vygotsky defende a construção de contextos de aprendizagem desafiantes, crucialmente dependentes da (colabor)ação com outros. Argumenta o autor que as crianças poderão vir a fazer mais do que aquilo que podem realizar sozinhas se, no contexto da sua participação em situações práticas estimulantes, recebem o apoio que estimula capacidades em maturação "através do diálogo que mantêm com os professores ou pares mais capazes" (VYGOTSKY, 1995, p. 180, tradução minha).

Presentemente, a discussão do princípio da prática situada na aprendizagem da 
literacia sublinha o papel instrumental desempenhado pelas Tecnologias de Informação e Comunicação (TIC). As TIC transformaram irrevogavelmente as práticas comunicativas que fazem uso da linguagem especializada. A utilização de recursos multimodais de construção de significado aliados a ferramentas de representação e veiculação de significados de natureza eminentemente social caracterizam muitas das atuais práticas de comunicação (MEDEIROS; PEREIRA; COUTINHO, 2016). As TIC têm, por isso, um papel incontornável na simulação das (novas) práticas de literacia na escola (COPE; KALANTZIS, 2009, 2010; DEDE, 2000; GEE, 2010).

Esse entendimento da prática situada na aprendizagem da literacia sustentou ativamente o meu trabalho de coordenação do PNEP no núcleo da Universidade do Minho, tendo orientado os formadores e professoresformandos nas escolas para o seu reconhecimento nas orientações e nos materiais especificamente construídos para o PNEP pelo Ministério da Educação ${ }^{1}$. Contudo, considero que, no contexto da exposição de um entendimento sociocultural da aprendizagem de crianças, é importante referir uma dimensão fundamental das suas atividades, nomeadamente a constituída pelo brincar. Tal como teorizado por Vygotsky, "A criança avança essencialmente através da atividade lúdica" (VYGOTSKY, 1979, p. 156, tradução minha). 0 brincar é o primeiro modo pelo qual as crianças se implicam com o mundo e "[p]ara a criança em idade escolar, o jogo não desaparece, antes se introduz na atitude que a criança adota face à realidade" (VYGOTSKY, 1979, p. 18, tradução minha). 0 brincar tem sido alvo de uma agenda investigativa muito ampla (BROOKER; BLAISE; EDWARDS, 2014), de que destaco três assunções relevantes para a concepção da prática situada na pedagogia da literacia no primeiro ciclo do ensino básico.

1- Esses materiais ainda estão disponíveis no site da DGIDC: http://www. dge.mec.pt/materiais-didaticos-elaborados-no-ambito-do-pnep (acesso em 20 dez. 2015).
O brincar tem sido concebido como uma atividade fundamental para a enculturação humana. Van Oers (2014, p. 60) argumenta que brincar é "basically a way of executing practices, not a special phenomenon that may exist outside practices or precede them". A imaginação, a aceitação voluntária de regras e níveis elevados de envolvimento e satisfação pessoal são características centrais do brincar (KRAVTSOVA, 2014; Van Oers, 2014; VYGOTSKY, 1979). As crianças implicam-se em brincadeiras, durante as quais exploram o potencial das situações culturais que recriam e imitam.

A investigação tem mostrado que o brincar evolui em períodos definidos durante a ontogênese (KRAVTSOVA, 2014; VYGOTSKY, 1979). Quando o período pré-escolar termina, "the rules of play come to the forefront and the imaginative situation moves towards the sidelines" (KRAVTSOVA, 2014, p. 25-26). Este é o período da emergência dos jogos regulados por regras nas práticas lúdicas das crianças, o que conduz Kravtsova a afirmar que "on a large scale, all learning activity of primary school children is play with rules" (KRAVTSOVA, 2014, p. 29). Durante esse período, que corresponde à faixa etária implicada no estudo, as formas anteriores do brincar, sobretudo o faz de conta fantasioso, também se transformam dado que "the content of play often becomes related to real life and real events" (KRAVTSOVA, 2014, p. 26). Tendo tido a oportunidade de brincar em situações totalmente fantasiosas (por exemplo, fazendo de conta que é um gatinho ou uma princesa), a partir da idade escolar as crianças tendem para a realização de jogos que têm origem na sua vida e estão relacionados com as suas identidades reais.

A atividade de brincar na educação tem sido "positioned as educational practice" (WO0D, 2014, p. 147). Wood (2014) categoriza três modos em que o brincar pode ser realizado como pedagogia: a) o brincar iniciado pela criança; b) o brincar guiado pelo adulto; c) o brincar de tipo tecnicista, politicamente instituído. Esses modos diferem quanto a 
quem toma as decisões sobre o brincar (a criança; o adulto, que segue o currículo, mas que é responsivo aos interesses das crianças; o currículo, respectivamente); quanto aos significados e aprendizagens construídos (de interesse para as crianças; na interação entre os objetivos da criança e do adulto e o currículo; exclusivamente definidos pelo currículo); assim como quanto ao formato das atividades realizadas (livre; estruturado pelos educadores; estruturado e programado pelo currículo). A assistência do adulto é fundamental para o desenvolvimento e a aprendizagem por meio do brincar, mesmo quando é a criança que assume o papel central nas atividades, como captado no primeiro modo (a) do brincar educativo.

\section{O estudo}

Durante o último ano de funcionamento do PNEP, recebi inúmeros relatos que davam conta do aparente sucesso da experiência educativa junto dos seus principais destinatários, os alunos. Este fato motivou a realização de um projeto de investigação para conhecer o que pensavam os alunos sobre a experiência vivenciada (PEREIRA; BRAGA; RIAÑO, 2015; PEREIRA; RIAÑO, no prelo). Uma das várias questões de investigação que orientaram esse estudo foi a seguinte: Que representações construiram as crianças sobre a prática que situou a aprendizagem da literacia?. Ela foi formulada com o objetivo de contribuir para a construção de conhecimento relevante para a pedagogia da literacia. A riqueza das respostas a essa pergunta justifica o destaque que lhe atribuo neste artigo.

\section{Metodologia}

Para poder responder de maneira aprofundada à pergunta de investigação, concebi um estudo de natureza qualitativa, com o objetivo de investigar os significados efetivamente construídos pelos alunos, procurando as suas descrições, explicações e interpretações da experiência vivenciada. No desenho do estudo foram levadas em conta as diretrizes metodológicas e éticas da investigação com crianças (SHAW; BRADY; DAVEY, 2011). Dado que o estudo se integrou a um programa no qual os alunos tinham estado a participar ativamente no âmbito do seu processo educativo normal, não foi requerida autorização para a realização desta avaliação (SHAW; BRADY; DAVEY, 2011, p. 32).

A estratégia de recolha de dados usada foi a entrevista em grupo. Trata-se de uma técnica particularmente adequada quando se pretende envolver crianças como informantes sobre a sua experiência de vida (COHEN; MANION; MORRISON, 2011; EINARSDOTTIR, 2014; LEWIS, 1992), oferecendo a possibilidade de coletar informação de forma rápida e eficiente em grupos de indivíduos que "have been working together for some time or common purpose" (WATTS; EBBUTT, 1987, apud COHEN; MANION; MORRISON, 2011, p. 373). 0 fato de todo o grupo poder interagir e discutir durante a conversa oferecia a possibilidade de as crianças apoiarem, ampliarem e generalizarem reflexões individuais na construção de uma perspectiva coletiva, que me pareceu uma unidade de análise adequada para o meu estudo (COHEN; MANION; MORRISON, 2011; LEWIS, 1992). Descartei o recurso a outras técnicas, como entrevista individual e grupo de foco, embora tivesse em conta algumas das suas características, como exporei abaixo.

0 conteúdo da entrevista, que se enquadrou no projeto de investigação, incluiu três grandes blocos de perguntas: o primeiro solicitou a opinião sobre as aulas do PNEP, aspectos mais e menos valorizados, exemplos e justificações; o segundo confrontou as crianças com a ideia de que as aulas foram diferentes (pergunta fechada motivada por apreciações idênticas frequentemente reportadas no núcleo de coordenação), seguida de uma pergunta de follow-up, solicitando explicitações e justificações; o terceiro incidiu na identificação das aprendizagens construídas. Apenas as duas primeiras perguntas são relevantes para 
conhecer percepções sobre a prática situada, em discussão neste artigo.

A recolha de dados foi conduzida pelos professores titulares de turma na presença e com a colaboração dos formadores do PNEP. Assumi que a relação de proximidade estabelecida durante pelo menos um ano letivo entre alunos, professores e formadores, reportada como muito amigável, garantiria rapport (equilíbrio nos poderes do entrevistado e entrevistador) no contexto da entrevista, permitindo a confiança necessária para as crianças revelarem o seu pensamento (COHEN; MANION; MORRISON, 2011; EINARSDOTTIR, 2014; FARGAS-MALET ET AL., 2010; MORGAN ET AL., 2002). Decorreu no contexto natural das aulas do PNEP, um ambiente não disruptivo que asseguraria o conforto necessário às crianças (COHEN; MANION; MORRISON, 2011; LEWIS, 1992), assim contribuindo para que o estudo adquirisse um caráter próximo do etnográfico (SAN FABIÁN, 2014; SAYWITZ; CAMPARO, 2014).

Os entrevistadores receberam um conjunto de orientações escritas. Entre outras indicações, pedi-lhes que ajudassem as crianças a compreender que se tratava de conversas destinadas a conhecer as suas perspectivas sobre as aulas e não para avaliá-los. Pedi também aos professores que verificassem a compreensão das questões e a clareza das respostas (COHEN; MANION; MORRISON, 2011; SAYWITZ; CAMPARO, 2014; SHAW; BRADY; DAVEY, 2011). Com essas precauções, era meu objetivo minimizar distrações, suscetibilidades e limitações linguísticas (LEWIS, 1992).

As entrevistas foram dirigidas aos alunos do segundo, terceiro e quarto anos, ficando ao cargo dos professores que lecionavam o primeiro ano a decisão de realizar a recolha de dados junto dos seus alunos em função da sua apreciação da autonomia das crianças para participar. Os facilitadores gravaram em áudio e, em alguns casos, em vídeo 128 entrevistas nas salas de aula de 128 professores formandos, envolvendo um número potencial de 2.360 crianças (média de 18,8 crianças por turma entrevistada). Os dados foram recolhidos por dezenove (de um total de 33) formadores, envolvendo dezenove agrupamentos de escolas da zona norte de Portugal abrangida pelo núcleo que coordenei. 0 conjunto de entrevistas recolhidas perfez um total de 31h23'37" de gravação. Todas as conversas tiveram lugar entre maio e junho de 2010.

As análises preliminares revelaram a existência de gravações inaudíveis, tendo o corpus final ficado reduzido a 106 entrevistas, com um total de 28h13'36" de gravação, envolvendo dados recolhidos por quinze formadores, implicando potencialmente 1.982 crianças. Preparei uma análise preliminar desse corpus para selecionar os exemplos mais informativos com base num conjunto de critérios formais e de conteúdo. Os critérios formais tiveram origem nas principais recomendações sobre a condução de entrevistas em grupo (COHEN; MANION; MORRISON, 2011; LEWIS, 1992), com a adaptação de alguns critérios sobre a realização de grupos de discussão (KRUEGER, 1991): selecionei entrevistas por grupo (assim mantendo um grupo natural e já habituado a trabalhar colaborativamente), com um único ano de escolaridade (para homogeneizar os dados), durante as quais várias crianças interviessem (denotando a existência de rapport). Procurei entrevistas com início e fim bem definidos, que permitissem perceber o fluxo da conversa e que fossem maximamente explícitas, deixando pouca ou nenhuma ambiguidade de interpretação. Procurei também a existência de foco durante a conversa, que é indicador da atenção e interesse das crianças (SHAW; BRADY; DAVEY, 2011). Procurei também manifestações de intersubjetividade (ANDERSON, 2008): muito embora tivesse valorizado as perspectivas subjetivas, prestei atenção especial à existência de interação entre as crianças durante a qual dessem continuidade aos contributos dos colegas, contribuindo para a construção de um entendimento comum, coletivo e consensual sobre o assunto em investigação (COHEN; MANION; MORRISON, 2011). Os critérios 
de conteúdo que sustentaram a seleção das entrevistas refletiram os significados em estudo no projeto de investigação que enquadrou este estudo: (i) expressão de opiniões e sentimentos; (ii) referência a características do processo de aprendizagem; (iii) identificação das aprendizagens construídas referentes a código, texto e gramática.

Realizei a análise formal e de conteúdo com um colaborador e com um avaliador voluntário, professor de primeiro ciclo. A triangulação dessa análise formal com a análise de conteúdo permitiu a identifıcação final de dezenove entrevistas como sendo maximamente relevantes para transcrição. Esse procedimento permitiu a identificação de cinco entrevistas por ano de escolaridade, exceto o terceiro ano, com quatro entrevistas. 0 tempo total de transcrição distribui-se do seguinte modo:

Tabela 1 - Tempo total das entrevistas transcritas por ano de escolaridade.

\begin{tabular}{llllll}
\hline Primeiro ano & Segundo ano & Terceiro ano & Quarto ano \\
\hline 01h23'44" & 00h53'32" & O0h58'48" & 1h00'54" \\
& & & & \\
\hline
\end{tabular}

Fonte: dados da pesquisa.

Nas transcrições, preservei a identidade dos intervenientes: às crianças foi atribuído um número (ex.: C12), e aos professores a letra (P). Construí um código para cada excerto transcrito, por exemplo 4XPZ6; 4XP1_6, constituído por ano (4) + identificação do formador (XP) + inicial do professor (Z) (ou um número (1), conforme disponibilização da identificação do professor) + página (6).

Por fım, realizei uma análise temática das entrevistas transcritas, procedendo do primeiro para o quarto ano. 0 entendimento de prática situada que operacionalizei durante o PNEP e que sintetizei no item Enquadramento teórico deste artigo orientou esta análise, que, contudo, permaneceu aberta à emergência de novos temas. Os excertos das entrevistas aqui usados foram adaptados para facilitar a sua inteligibilidade.

\section{Resultados}

A análise temática dos dados recolhidos por meio da entrevista em grupo permitiu a identificação de um conjunto muito fértil de significados recorrentes. Estes foram agrupados em (i) opiniões e sentimentos e (ii) representações sobre a prática situada, sendo de referir que a informação sobre este último tema foi recolhida no âmbito das justificações dadas pelas crianças para todas as questões colocadas.

\section{(i) Opiniões e sentimentos}

A resposta à pergunta sobre opiniões e sentimentos construídos sobre as aulas foi surpreendente: as crianças gostaram muito do PNEP. Associaram felicidade, gosto e prazer à sua experiência, expressando opiniões muito positivas e sentimentos muito favoráveis e fortes:

\begin{tabular}{|c|c|}
\hline $\begin{array}{c}\text { As aulas foram superdivertidas; } \\
\text { trabalhávamos de forma divertida; } \\
\text { fantásticas; engraçadas; muito boas; } \\
\text { bonitas; muito interessantes; desafiantes; } \\
\text { Opiniões positivas } \\
\text { ótimas; originais; criativas; muito ativas; } \\
\text { importantes; mágicas; o PNEP foi formativo; } \\
\text { empolgante; [uma forma de trabalhar que] } \\
\text { é nova para mim; é motivadora; muito } \\
\text { emocionante... excitante. }\end{array}$ \\
\hline Sentimentos \\
favoráveis \\
$\begin{array}{c}\text { Adoramos estas aulas; gostei muito das } \\
\text { aulas; gostei muito do que nós fizemos no } \\
\text { PNEP; gostei de tudo; gostava de continuar } \\
\text { a fazer o PNEP }\end{array}$ \\
\hline
\end{tabular}

As opiniões e sentimentos expressos foram muitas vezes justificados com referência à forma como aprenderam, assim apontando para a relevância da prática (situada) na aprendizagem, tal como ilustrado nos excertos abaixo, o primeiro dos quais de uma criança de primeiro ano:

P: Diz-me lá, tu gostaste das aulas?

C7: Não gostei, adorei.

P: Aí sim? Por quê?

C7: Porque fizemos sempre aulas diferentes e estávamos sempre a aprender. (1AL4). 
Um aluno de quarto ano afirmou: "C6: $\mathrm{Eu}$, estas aulas, achei-as muito divertidas, deviam ter sido feitas muitas mais vezes, foram muito criativas e tenho uma certeza: foram muito melhores que cópias!" (4ARG1), também justificando a sua opinião com trabalho realizado para aprender. 0 mesmo se verifica no seguinte excerto, que é também relevante por revelar uma instância de intersubjetividade. A professora apoia a $\mathrm{C} 5$ a sumariar a opinião que tinha dado usando um adjetivo (conteúdo de aprendizado referido durante a conversa) e uma outra criança (C7) não pôde evitar contribuir com o seu próprio adjetivo:

P: Para ti, então, foi... Diz-me numa palavra: Como é que descreves o PNEP? Vês, agora vais pôr aí um adjetivo!

C5: Muito fixe!

P: Está bem (risos).

C7: Eu acho que o PNEP foi uma coisa nova que acho que nunca tinha visto assim, nunca tinha participado numa aula como estas. Acho que foi nova e espero fazê-la outra vez. (4ARD2).

Minutos mais tarde, os mesmos alunos se emocionam ao ver uma sequência de slides (vídeo) que a professora preparara com fotografias das sessões de trabalho. Novamente a justificação dada para essa emoção aponta para a forma de aprender:

P: E aqueles meninos que choraram, todos se emocionaram. Por que o choro?

C5: É choro de felicidade (emocionado)! É choro de alegria!

P: De alegria, por quê?

C5: Estamos a trabalhar bem e... (chora) (4ARD16).

\section{(ii) Representações sobre a prática situada}

Os significados que as crianças expressaram sobre a forma como aprenderam foram particularmente reveladores. A análise permitiu, em particular, uma reconstrução muito interessante da percepção sobre a prática situada, que, em meu entender, esclarece cabalmente as opiniões e sentimentos manifestados.

\section{Um processo motivador e eficaz}

São inúmeras as evidências de que as aulas foram motivadoras:

C2: Gostei das aulas do PNEP, porque aprendemos assim "desafios" para aprender (2ZM2).

C12: Começamos a aprender melhor a língua portuguesa. (3LA8).

C9: 0 PNEP foi para descobrir novas coisas e para nós foi novas aventuras que nós fizemos. (4ARD3).

Foram relativamente escassas expressões de dificuldade na aprendizagem, quase todas de crianças do primeiro ano:

C1: 0 que eu menos gostei foi da receita do bolo de leite.

$\mathrm{P}$ : Porque é que gostaste menos?

C1: Porque tínhamos muito trabalho e era um bocado difícil.

P: Achaste difícil?

C1: Um bocado.

C12: Eu não achei. (1CA4).

A opinião da C1 é contrária ao significado grupal que estava (e continuou) a ser construído, de que a C12 é aqui representativa. Ainda a propósito da percepção de não dificuldade na construção da aprendizagem, um aluno do 4. ${ }^{\circ}$ ano afirma: "C8: Eu acho que não foi difícil, porque quando estamos a aprender e nos estamos a divertir nada é difícil, nem aborrecido, tudo é divertido e com grandes aprendizagens." (4ARP4).

Um processo de aprendizagem singular

Nas vozes das crianças destacou-se a percepção de que as aulas do PNEP foram diferentes, 
o que em alguns casos emergiu na conversa antes mesmo de serem questionadas sobre essa diferença:

C2: Antes de termos as aulas do PNEP, as aulas eram iguais, aprendíamos normalmente. (3LA7).

C1: Gostei porque foram interessantes e nos ensinaram muitas coisas de maneiras diferentes. (3VL1).

C13: Dantes nas aulas era diferente porque o professor explicava e depois nós tínhamos que fazer aquela ficha. E no PNEP não. No PNEP explica, depois nós fazemos atividades diferentes. (4ARD5).

Os contributos das crianças a este respeito permitiram associar a diferença percebida nas aulas a quatro grandes temas: atividade, ludicidade, colaboração e mediação TIC, permitindo, desse modo, a caracterização da implementação da prática situada no contexto do PNEP.

\section{Um processo de aprendizagem ativo}

A análise desvelou que a aprendizagem foi marcada por uma intensa atividade dos aprendentes. A esse respeito, um aluno do primeiro ano referiu: "Trabalhamos muito" (1CA1), opinião comum a todos os alunos, que perceberam a sua atividade como diferente: " $\mathrm{C} 4$ : $\mathrm{Eu}$ acho que eram diferentes, porque as aulas do PNEP eram mais movimentadas (4TM23)". As suas vozes deixaram perceber que o livro de texto não desempenhou um papel de destaque

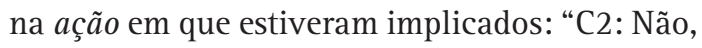
trabalhamos em outras... não é com os livros... trabalhamos com as nossas ideias" (3AL1), fato que um aluno de quarto ano também evocou para justificar a sua percepção de que as aulas não foram normais:

C3: A minha opinião sobre as aulas do PNEP é que foi divertida a maneira de aprender, que nós aprendemos mais do que estar a dar uma aula normal como os outros professores.

P: 0 que é uma aula normal para ti?

C3: Uma aula normal é: vamos dar aquela matéria e vamos ler o livro, começamos a estudar; pela forma do PNEP, ainda aprendíamos mais do que do livro. (4ARD1).

Na perspectiva das crianças, a aprendizagem foi claramente contextualizada pela sua própria agentividade, deixando perceber que estiveram muito ativamente implicados em práticas na aprendizagem de literacia. Verbos como fazer, construir, sublinhar, usar, colar, registrar, gravar, selecionar, apresentar, escolher, procurar, pesquisar, descobrir, organizar, entre muitos outros, conjugados na primeira pessoa do singular ou do plural, como profusamente ilustrado nos excertos usados neste artigo, são um poderoso indício dessa implicação em situações de aprendizagem prática.

\section{Um processo de aprendizagem lúdico}

A análise detida dos significados mostrou que a singularidade percebida também se associou estreitamente à natureza lúdica da prática experimentada, e esse foi o tema mais inesperado revelado pela análise:

C6: No PNEP nós fazemos assim... não são bem jogos, são tipo jogos que nós aprendemos a fazer as coisas de maneira diferente e nós conseguimos decorar melhor aquilo na nossa cabeça.

P: Muito bem. Então, o PNEP trouxe uma forma de ver as coisas e de guardar as coisas na memória, é isso?

C6: Sim.

P: Por causa dos jogos?

C6: Sim, através dos jogos nós conseguimos agora ver melhor as coisas. Mas ao fazer os jogos divertimo-nos e, ao mesmo tempo que nos divertimos, também aprendemos. (4ARD4-5). 
Todos os grupos concordaram em que as aulas foram divertidas, dando testemunho de um grande prazer na aprendizagem. Nas vozes das crianças, percebe-se que o brincar (em geral) e o jogo e o faz de conta (em particular) foram as formas de brincar que situaram as aprendizagens construídas:

C14: Aprendemos jogos de trabalho. (1CA3).

C7: Gostei das aulas do PNEP porque fizemos jogos. (2ZM2).

C12: $\mathrm{Eu}$ gostei destas aulas porque aprendemos coisas novas sob a forma de brincar. (3JR2).

Com efeito, os dados mostram a valorização de jogos com regras, tematicamente relacionados com a realidade sociocultural próxima das crianças. As vozes das crianças também revelaram que experienciaram uma forma muito estruturada de jogo educativo, que claramente valorizaram. Os professores aparentemente controlaram todas as tarefas realizadas, orientadas a objetivos de natureza curricular, não surgindo nenhuma evidência de brincadeiras geridas pelas crianças no contexto da aprendizagem da literacia. Os exemplos seguintes ilustram esses achados, ao mesmo tempo em que testemunham a existência de uma subcategorização da atividade lúdica experimentada.

\section{(i) 0 brincar na aprendizagem autossustentada da literacia}

As crianças detalharam muitas instâncias de atividades de aprendizagem e de treino de diferentes dimensões da linguagem especializada relacionadas com código, texto e gramática. Os seus testemunhos deixam perceber que as atividades lúdicas situaram claramente essas aprendizagens. Um exemplo recorrente entre os alunos de alfabetização foi o loto. Nesse jogo "C15: tínhamos um cartaz com imagens e depois a professora deu-nos umas palavras [escritas] e depois todos tirávamos uma palavra [do saco] e a professora [lia-a] e depois quem tivesse punha-a... (1CA9). Tratou-se de um jogo destinado a ajudar as crianças " $\mathrm{C} 4$ : a identificar as palavras” (1CA11), promovendo o primeiro contato e memorização da forma escrita de palavras (oralmente) familiares e a leitura inicial. No seguinte exemplo, a ludicidade manifesta-se no recurso ao faz de conta. A partir do que a criança diz, percebe-se que a tarefa tinha por objetivo a aprendizagem de dimensões orais da linguagem especializada:

C6: Aprendi a expressar-me à frente de mais pessoas, já não tenho agora tanta vergonha como tinha no início do ano porque agora também fizemos uma peça de teatro à frente dos nossos pais, [e também] quando nós tivemos que escolher uma personagem para os outros adivinharem qual é que nós éramos... e eu escolhi o D. Afonso Henriques e eu fiz coisas, fiz uma espada de pau... uma túnica... uma coroa de papel e também escrevi o papel do que eu tinha de dizer para os meus colegas adivinharem que personagem é que eu era. (4ARD 10).

\section{(ii) 0 brincar na prática teleológica de literacia}

A análise revelou também outros casos de práticas de literacia realizadas com outros fins para além dos estritamente associados à aprendizagem da literacia. Tratou-se de situações em que foram construídos significados relacionados com diversas aprendizagens curriculares, que assim situaram a aprendizagem de aspetos relevantes da literacia implicados nessas práticas, como, por exemplo, aprendizagem de processos de leitura e de escrita de gêneros de texto especializados. As vozes das crianças mostram que captaram essas práticas como lúdicas.

Em muitos casos, a prática de literacia teleológica envolveu a assunção de um determinado role sociocultural, um faz de conta claramente associado à realidade, ilustrado no 
seguinte exemplo da área curricular de ciências, uma situação veladamente desencadeada pela professora com o envio de uma carta:

C13: Eu gostei da aula em que mandamos a carta à Electra porque gostei de ajudar a Electra a perceber o que era a poluição e também gostei porque foi para não deixar a Electra sem resposta e preocupada com a poluição que havia no local onde ela vivia. (4ARP3).

Nesta situação, o role de um ecologista foi "jogado" numa prática de literacia com uma intenção social que situou a aprendizagem da escrita de um gênero de texto especializado (a carta). No seguinte exemplo, o brincar assumiu a forma de um jogo, que implicou o treino de conhecimento matemático e a aprendizagem de um gênero de texto específico dos jogos, as instruções:

P: Mas, dessas [aulas] todas, se tivesses que escolher uma, qual é que escolhias?

C8: 0 jogo do banqueiro.

P: E porquê o jogo do banqueiro? 0 que é que fizeram nessa aula para gostarem tanto dela?

C8: Fizemos um jogo.

P: E era um jogo de quê? Era de futebol, era de bola?

Grupo: Matemática.

P: Esse jogo era de língua portuguesa ou era de matemática?

Grupo: Matemática.

C9: Foi de língua portuguesa e de matemática.

P: As instruções eram de matemática?

Grupo: Não!

C10: Eram de língua portuguesa.

P2: Então que tipo de texto era esse?

Grupo: Era um texto instrucional. (2TM2).

0 interesse do seguinte exemplo advém do contraste que institui com o prazer manifestado pela generalidade dos alunos acerca da forma como construíram as suas aprendizagens. Ouvimos a opinião negativa de um aluno sobre atividades realizadas em ciências que, para além das aprendizagens sobre plantas, também situou a aprendizagem sobre a escrita de textos. Apesar do reconhecimento de que aprendeu, esta criança deixa perceber que a prática que experienciou não proporcionou nenhum tipo de satisfação pessoal, provavelmente por ser demasiado séria ou "adulta":

C10: A aula de que eu gostei menos foi quando nós estávamos sempre a trabalhar as plantas, plantas, plantas, plantas, plantas... Eram também trabalhos de casa sobre plantas. Eu parecia que só via tudo em plantas, plantas, plantas, plantas...

P: Esse trabalho todo das plantas foi para fazerem o quê? [...] Diz-me uma coisa, gostaste menos porquê? Porque era cansativo ou porque era chato ou porque achavas que não ias aprender nada com aquilo?

C10: Ora bem, aprender, aprendi! Mas era um bocadinho cansativo... Era quase sempre plantas, plantas, plantas, e eu não achei essa aula muito interessante.

$\mathrm{P}$ : Achaste mais cansativa?

C10: Sim.

P: Mas então agora deixa-me perguntar-te uma coisa. Levaste esse trabalho todo para quê? Para aprender a escrever...

C10: Textos.

P: Textos. Achas que depois desse trabalho todo que levaste já sabes escrever melhor um texto? Achas que valeu a pena ou não? C10: Olhe, antes eu pensava mal, agora penso melhor... agora penso que aquela trabalheira toda foi até foi...

P: Útil, não?

C10: Útil para aprender a escrever textos melhor. (3LA6-7).

Um processo de aprendizagem colaborativo

A valorização da colaboração na construção da aprendizagem foi um tema recorrente em todas as entrevistas. Nas 
vozes dos alunos, esse tema também foi consideravelmente elaborado com explicações e justificações:

C5: Gostei mais dos trabalhos em grupo (1CA2).

C2: Eu quero dizer mais uma coisa professora.

P: Então diz lá.

C2: Eu acho que colaborei muito. (2CA4).

C9: Eu a parte que mais gostei no PNEP foi a parte dos trabalhos em grupo que fizemos porque trabalhando em grupo podemos fazer mais coisas, temos mais ideias. (4JR3).

C13: No PNEP aprendemos a colaborar com os nossos colegas nos trabalhos de grupo e a dar a nossa opinião. (4ARG5).

A colaboração foi percebida como parte da singularidade do processo de aprendizagem proporcionado pelo PNEP em todas as entrevistas. No seguinte exemplo, captado numa turma de terceiro ano a propósito da questão sobre as diferenças percebidas, as crianças revelam um elevadíssimo grau de consciência sobre a realização de trabalho conjunto nas aulas PNEP e de como esse tipo de trabalho se diferenciou das aulas da professora $\mathrm{H}$. Nesse caso, a professora do PNEP, que conduz a entrevista, não era a professora $\mathrm{H}$, a sua professora habitual, situação relativamente frequente dada a possibilidade de qualquer professor de uma escola, com ou sem turma de alunos atribuída, participar na formação PNEP, em cujo caso o processo de supervisão decorreria na turma de outro docente. Ao escutar as vozes destes alunos, é muito perceptível a preferência pelo modo colaborativo de aprender experimentado nas aulas, manifestamente associado ao caráter agentivo. Além disso, percebe-se como são críticos das aulas habituais da professora $\mathrm{H}$, caracterizadas pelo silêncio, atenção, trabalho individual e memorização:

C5: Acho que as aulas do PNEP foram diferentes.

\section{P: E por quê?}

C5: Porque fizemos várias coisas.

P: Por exemplo...

C5: Por exemplo: trabalhar em grupo. Não

é todos os dias que fazemos isso.

$\mathrm{C} 1$ : Houve uma grande diferença porque nas outras aulas temos de estar concentrados, lá temos que estar a aprender para o quadro, $\mathrm{e}$ nessas aulas não: tínhamos a oportunidade de experimentar coisas novas, de viver coisas que ainda não tínhamos vivido na vida e gostei.

C2: São diferentes porque com a professora $\mathrm{H}$ cada um tem de pensar por si, e nas aulas do PNEP há aulas em que trabalhamos em grupo e aí já não é igual às aulas da professora $\mathrm{H}$.

C4: Foram muito diferentes porque nós trabalhamos em grupo e tínhamos que apresentar o que escrevíamos, e nas aulas da professora $\mathrm{H}$ não.

C10: Para mim são diferentes porque nós, com a professora $\mathrm{H}$, temos que estudar, depois dizemos as coisas à professora $\mathrm{H} \mathrm{e}$ depois quando vimos para aqui já temos tudo na cabeça.

C9: Nas aulas da professora $\mathrm{H}$ nós trabalhamos para nós e nas aulas PNEP já podemos trabalhar em grupo. Por exemplo, se nós não compreendermos qualquer coisa, os outros alunos já nos podem ajudar. (4JR3-5).

Um processo de aprendizagem mediado pelas TIC

Nas entrevistas, as crianças se referiram muitas vezes ao recurso às TIC nas suas práticas, que foi percebido como desempenhando um papel importante na aprendizagem em todos os anos escolares, sendo muito frequentemente destacada a novidade que essa utilização significou. Entre muitos outros exemplos, os alunos referiram-se ao uso do PowerPoint para apresentar o seu trabalho (colaborativo) assim como ao uso do Word para escrever textos e de recursos áudio para gravar e escutar histórias inventadas e contadas. A internet teve um papel 
de suporte inovador muito evidente nas práticas de literacia teleológica de muitos alunos:

C9: Aprendemos também a pesquisar na internet para sermos mais rápidos a encontrar as coisas, em vez de pesquisar nos livros. (3VL2).

C6: Estas aulas do PNEP foram diferentes porque em vez de estar a ouvir a professora, as explicações, pesquisei. (4ARG4).

C17: Nestas aulas do PNEP aprendi a pesquisar e a recolher informação da internet porque na biografia de Sá de Miranda, nós aprendiamos, tínhamos de ir buscar informação sobre a vida dele [à net], e depois fizemos histórias sobre ele. (4ARG5).

Os alunos também valorizaram a criação de blogs de turma, a que se referiram como contexto de (novas) práticas de escrita e como instrumento de aprendizagem, comunicação (entre colegas e fora da escola), prazer e diversão:

C4: Eu fui deixando comentários e fui lendo os nossos textos que estavam lá para ver se estavam bem...(4JR9).

C14: Podemos partilhar as nossas ideias com muito mais pessoas que estão fora mas veem os nossos trabalhos. (4JP10)

C6: Há muitas coisas que nós podemos aprender com os sites que há na internet e com os blogs que há de outras turmas. (4JP13).

Uma turma usou o seu blog para criar uma biblioteca digital, que claramente motivou muito os alunos para novas formas de leitura:

C14: Os livros digitais, também não sabia que existiam, mas, a partir de agora, como tive conhecimento que existiam, ando sempre a ler.

C7: Eu dantes também não sabia que existiam livros digitais, mas, como a C14 disse, também agora habituei-me a lê-los no nosso blog.

C3: Eu também não conhecia, fiquei surpreendido e agora gosto.

C5: Às vezes deixo lá alguns comentários, gosto de fazer lá exercícios... também no tempo depois de acabar de fazer os trabalhos de casa leio alguns livros digitais (4JR9).

\section{Discussão}

Os resultados das análises fundamentam concepções atuais referentes à realização de pesquisa com crianças, particularmente a conceitualização das crianças como atores sociais de pleno direito e experts em assuntos referentes às suas próprias vidas, de que são informantes legítimos (EINARSDOTTIR, 2014; FARGAS-MALET; et al., 2010; SHAW; BRADY; DAVEY, 2011). Por outro lado, este estudo permite também assumir a viabilidade da realização de entrevistas em grupo com crianças dos sete aos dez anos como instrumentos de recolha de dados em circunstâncias de amplo apoio e contextualização apropriada (SHAW; BRADY; DAVEY, 2011). Considero inestimável o resultado da sua realização para a construção de um entendimento da prática situada na aprendizagem da literacia nos anos iniciais do ensino fundamental.

Os resultados da análise corroboraram muito claramente a importância, ao mesmo tempo em que ilustraram contornos do princípio da prática situada na aprendizagem da literacia. A ação linguística colaborativa e mediada pelo uso das TIC contextualizou a aprendizagem da linguagem especializada em que as crianças se estavam a iniciar - código, texto e gramática -, tendo sido muito valorizada pelos alunos, assim corroborando a teorização da prática situada construída no âmbito dos New Literacy Studies (THE NEW LONDON GROUP, 2000; COPE; KALANZIS, 2009, 2010). Contudo, os mesmos resultados apontam inequivocamente para a necessidade de uma redefinição desse mesmo 
enquadramento no sentido da consideração da atividade do brincar na concepção e aplicação do princípio da prática situada nas séries iniciais do ensino fundamental.

A análise temática das representações das crianças permitiu identificar o papelchave desempenhado pela prática lúdica na experiência de aprendizagem vivenciada (VYGOTSKY, 1979). As percepções dos alunos mostraram que foram iniciados e conduzidos, brincando, no caminho da aprendizagem da dimensão cultural constituída pela literacia. É aqui particularmente pertinente fazer referência aos estudos que têm explorado a emergência da literacia nas concepções das crianças antes da iniciação formal das aprendizagens (ADAMS, 1990; FERREIRO, 2003).

0 conceito de literacia emergente define a intensa conceptualização sobre literacia que as crianças em idade pré-escolar constroem como resultado da sua interação com (e interesse pelo) o mundo sociocultural que os rodeia. Os estudos da literacia emergente sugerem, pois, que a literacia se configura como um domínio cultural potencial do brincar para aprender das crianças durante o $10^{\circ}$ ciclo, dada importância crítica que essa dimensão da vida já adquiriu para a formação das suas identidades no momento da iniciação dessa aprendizagem. Entrando para a escola, essas crianças sabem que vão aprender literacia, e teoricamente esperam aprendê-la à sua maneira. Os dados analisados mostram como a atividade de aprendizagem da literacia experienciada por estes alunos se configurou efetivamente como um jogo de aprendizagem. Em qualquer um dos tipos de práticas lúdicas identificados, os alunos aprenderam e praticaram regras e procedimentos que aceitaram como necessários para participar em práticas de literacia mais tarde na vida, relegando a imaginação fantasiosa para um segundo plano (KRAVTSOVA, 2014):

C7: Nas aulas do PNEP nós melhoramos bastante e eu melhorei bastante a ler e a escrever, que são uma coisa importantíssima para o nosso futuro, que, se Deus quiser, iremos ter uma profissão. (4ARP5).

É como se a C7 dissesse: Isto ainda não é bem a nossa vida, mas este jogo educativo está a preparar-nos para a nossa futura vida real!

No PNEP, a aprendizagem lúdica foi abertamente enquadrada por um currículo, instituído politicamente (tal como referido na parte introdutória deste artigo), no desenvolvimento do qual, e na perspectiva dos aprendentes, a ludicidade assumiu um papel instrumental: brincou-se para aprender esse currículo, embora de uma forma altamente estruturada porque controlada pelos professores. Wood (2014) defende que tais casos de pedagogia estruturada do brincar correm o risco de diminuir a ligação afetiva que os alunos atribuem à aprendizagem, mas tal não foi o que aconteceu. Os dados mostram como as crianças se engajaram prazerosamente nessas atividades, como aparentemente fazem quando se iniciam ludicamente em qualquer forma ou prática da cultura que desejam aprender para assim se tomarem membros plenos da sua cultura (VAN OERS, 2014). No meu entendimento, esse risco não se verificou precisamente por causa de o jogo de aprendizagem da literacia ter sido jogado à medida dos aprendentes, isto é, por ter sido responsivo às disposições destes aprendentes, que, como antes referido, fazem do jogo regulado por regras e orientado para a realidade o seu modo preferido de aprender (VAN OERS, 2014; KRAVTSOVA, 2014).

Os resultados sugerem, portanto, a valorização do jogo como uma dimensão incontornável da prática situada de aprendizagem da literacia nos primeiros anos do ensino. A ludicidade parece mesmo ter sido a característica central da prática percebida e valorizada pelos alunos, emergindo como a principal justificação para afırmações como "C13: É muito bom trabalhar" (2ZM3), uma opinião de um aluno de segundo ano que se repetiu em todo o corpus de entrevistas. Esta conclusão está em sintonia com a defesa de que, 
na sua transição para a aprendizagem formal, "children need more challenging forms of play that support progression towards social and symbolic complexity" (WOOD, 2014, p. 153). Em função do exposto, defendo que a concepção teórica de prática situada apresentada pelo The New London Group (2000) e reforçada por Cope e Kalantzis (2009, 2010) parece limitada no que diz respeito à aprendizagem da literacia nos anos inicias do ensino fundamental por não reconhecer o papel desempenhado pelo lúdico na aprendizagem: dimensão incontornável, do ponto de vista dos aprendentes, da ação colaborativa (e mediada pelas TIC) com a linguagem especializada em aprendizagem.

\section{Conclusões}

A investigação que relato neste artigo procurou identificar características da prática situada na aprendizagem da literacia nas séries iniciais do ensino fundamental. 0 estudo investigou esse objeto na perspectiva dos próprios aprendentes implicados numa experiência de aprendizagem excepcional e descortinou a vivência de um contexto diferente de aprendizagem da literacia, na forma de um jogo percebido como muito eficaz, motivador, prazeroso, ativo, colaborativo e mediado pelas TIC, em vez de um conjunto de atividades mecanicistas e obrigatórias, com regras fixas e estritas. As perspectivas das crianças apontaram para a adequação da concepção de uma pedagogia da literacia de raiz eminentemente sociocultural que subjaz a formulações atuais do princípio da prática situada, reclamando, contudo, para a ludicidade o papel central na sua conceitualização nas primeiras séries do ensino fundamental.

Nessa medida, este estudo configura-se como um contributo relevante para processos de análise e de tomada de decisão curricular sobre a concepção da pedagogia da literacia, seja no âmbito da definição de programas para os alunos, seja no desenho de unidades curriculares de cursos de formação inicial e contínua de professores.
0 resultado deste estudo justifica a realização de investigação subsequente que permita aprofundar o entendimento da prática situada na aprendizagem da literacia aqui reconstruído e, eventualmente, a sua ampliação. Uma dimensão importante é a da qualidade da interação professor-aluno(s)aluno(s), que este estudo, realizado em diferido das situações de aprendizagem e centrado nas perspectivas dos alunos, não teve capacidade de captar. Dois tipos de pesquisa emergem como especialmente pertinentes. Por um lado, estudos de tipo etnográfico e longitudinal, com a finalidade de conhecer detalhadamente os meandros (e efeitos, medidos na prática e não apenas nas percepções dos aprendentes) da prática situada descortinada nesta investigação, emergindo como especialmente pertinente a exploração das representações dos professores sobre a construção dessa mesma prática. Por outro, estudos de tipo transversal, com a finalidade de compreender a construção, realizada pelos professores implicados no PNEP, da pedagogia situada de caráter lúdico. Nos termos de Wood (2014), o caso que investiguei ilustra uma quase technicist version of play, pois, apesar de o currículo de aprendizagem ter sido centralmente definido, o brincar e o jogo não foram de modo algum previstos nos documentos políticos que fundaram o PNEP e nunca foram assunto explícito nas discussões de preparação de formadores e professores que comigo trabalharam. Disso são evidências inequívocas algumas reações de professores que, durante as entrevistas, manifestaram estranheza e preocupação perante a insistência das crianças em referir o aprender a brincar:

P: [uma forma de aprender] Motivadora, não foi? Não andamos aqui a brincar, embora tivessem gostado muito. Vocês gostaram tanto que até lhe chamam de brincar, mas não foi brincar, pois não? (4ARG3).

0 meu olhar retrospectivo leva-me agora a reconhecer a presença tácita do brincar 
nos exemplos práticos que os professores estudaram com os formadores e que de algum modo levaram para as suas salas de aula. Configura-se, por isso mesmo, a questão sobre o modo como os professores edificaram um uso instrumental (aparentemente tão eficaz) do lúdico quando esse aspecto foi teoricamente invisível para si próprios.

\section{Referências}

ADAMS, Marilyn Jager. Beginning to read: thinking and learning about print. Cambridge: MIT Press, 1990.

ANDERSON, Kate T. Intersubjectivity. In: GIVEN, Lisa M. (Ed.), The SAGE encyclopaedia of qualitative research methods. Thousand Oaks: SAGE, 2008, p. 467-468.

BROOKER, Liz; BLAISE, Mindy; EDWARDS, Susan (Ed.). The SAGE handbook of play and learning in early childhood education. London: SAGE, 2014.

COHEN, Louis; MANION, Lawrence; MORRISON, Keith. Research methods in education. London: New York: Routledge, 2011.

COMISSÃO NACIONAL DE COORDENAÇÃO E ACOMPANHAMENTO DO PNEP [CNA]. Programa Nacional de Ensino do Português no $1^{\circ}$ ciclo do Ensino Básico (PNEP). Lisboa: Ministério da Educação, 2006. p. 1-13. Documento manuscrito de circulação interna.

COPE, Bill; KALANTZIS, Mary. A multiliteracies perspective on the new literacies. In: BAKER, Elizabeth (Ed.). The new literacies: multiple perspectives on research pratice. New York: The Guilford Press, 2010. p. 105-135.

COPE, Bill; Kalantzis, Mary. "Multiliteracies": new literacies, new learning. Pedagogies, v. 4, n. 3, p. 164-195, Aug. 2009.

DAY, Christopher. Desenvolvimento profissional de professores: os desafios da aprendizagem permanente. Porto: Porto Editora, 2001.

DEDE, Chris. Emerging influences of information technology on school curriculum. Journal of Curriculum Studies, Abingdon, v. 32, n. 2, p. 281-303, 2000.

EINARSDOTTIR, Johanna. Children's perspectives on play. In: BROOKER, Liz et al. (Ed.). The SAGE handbook of play and learning in early childhood. Los Angeles: SAGE, 2014. p. 319-329.

FARGAS-MALET, Montserrat et al. Research with children: methodological issues and innovative techniques. Journal of Early Childhood Research, Thousand Oaks, v. 8, n. 2, p. 175-192, 2010.

FERREIRO, Emilia. Alfabetização e cultura escrita. Escola Nova: Revista do Professor, São Paulo, 2003.

GEE, James Paul. A situated-sociocultural approach lo literacy and technology. In: BAKER, Elizabeth A. (Ed.). The new literacies: multiple perspectives on research practice. New York: The Guilford Press, 2010. p. 165-193.

GEE, James Paul. Reading as situated language: a sociocognitive perspective. Journal of Adolescent \& Adult Literacy, Hoboken, v. 44, n. 8, p. 714-725, 2001.

GEE, James Paul. Situated language and learning: a critique of traditional schooling New York: London: Routledge, 2004.

GEE, James Paul. Social linguistics and literacies: ideology in discourse. 3. ed. London: Taylor \& Francis, 2007.

HALLIDAY, Michael Alexander Kirkwood. Towards a language-based theory of learning. Linguistics and Education, Amsterdã, v. 5, n. 2, p. 93-116, 1993.

KEMMIS, Stephen; MCTAGGART, Robin. Como planificar la investigación acción. Barcelona: Laertes, 1987.

KRAVTSOVA, Elena. Play in the non-classical psychology of L. S. Vygotsky. In: BROOKER, Liz et al. (Ed.). The SAGE handbook of play and learning in early childhood education. London: SAGE, 2014. p. 21-30,

KRUEGER, Richard A. El grupo de discusión: guía practico para la investigación aplicada. Madrid: Pirámide, 1991.

LATORRE, Antonio. La investigación-acción: conocer y cambiar la práctica educativa. Barcelona: Graó, 2003.

LEWIS, Ann. Group child interviews as a research tool. British Educational Research Journal, Hoboken, v. 18, n. 4, p. 413-421, 1992. 
MEDEIROS, Maria Ana; PEREIRA, Íris Susana Pires; COUTINHO, Clara. Narrativa digital: experimentar, explorar e reinventar a narrativa na geração Web 2.0. In: AZEVEDO, Fernando (Org.). Leitura e educação literária. Lisboa: Lidel, 2016. p. 59-73.

MORGAN, Myfanwy; GIBBS, Sara; MAXWELL, Krista; BRITTEN, Nicky. Hearing children's voices: methodological issues in conducting focus groups with children aged 7-11 years. Qualitative Research, Thousand Oaks, v. 2, n. 1, p. 5-20, Apr. 2002.

PEREIRA, Íris Susana Pires. Para a caracterização do contexto de ensino-aprendizagem da literacia no $1^{\circ}$ ciclo de escolaridade: das competências dos alunos às concepções e práticas dos professores. 2008. Tese (Doutorado em Estudos da Criança) - Instituto de Estudos da Criança da Universidade do Minho, Braga, 2008.

PEREIRA, Íris Susana Pires. Para um entendimento da complexidade da aprendizagem da leitura. In: VIANA, Fernanda Leopoldina; RIBEIRO, Iolanda; BAPTISTA, Adriana. (Ed.) Ler para ser: os caminhos antes, durante e... depois de aprender a ler. Coimbra: Almedina, 2014. p. 93-119.

PEREIRA, Íris Susana Pires. Sobre a natureza metodológica do Programa Nacional de Ensino do Português: opções e apostas do núcleo da Universidade do Minho. In: PEREIRA, Íris Susana Pires (Coord.). 0 ensino do português no 1. ${ }^{\circ}$ ciclo do ensino básico: construção de saberes profissionais no contexto do PNEP e do novo programa de português. v. 1. Braga: Instituto de Educação da Universidade do Minho, 2010a. p. 9-44.

PEREIRA, Íris Susana Pires. Um desenho global para o ensino da língua no $1 .{ }^{\circ}$ ciclo do ensino básico. In: PEREIRA, Íris Susana Pires (Coord.). 0 ensino do português no $1^{\circ}$ ciclo do ensino básico: construção de saberes profissionais no contexto do PNEP e do novo programa de português. v. 1. Braga: Instituto de Educação da Universidade do Minho, 2010b. p. 45-156.

PEREIRA, Íris Susana Pires; BRAGA, Ana Cristina; RIAÑO, Xosé González. Avaliação do Programa Nacional de Ensino do Português (PNEP) 1. ${ }^{\circ}$ ciclo: As perceções dos alunos. Revista Portuguesa de Educação, Braga, v. 28, n. 2, p. 51-86, 2015.

PEREIRA, Íris Susana Pires; RIAÑO, Xosé González. Elementary students' perspectives on a curriculum for literacy education. Research Papers in Education, Abingdon, no prelo.

SAN FABIÁN, José Luis. Evaluar programas socioeducativos en tiempos de crisis: un enfoque organizacional. Oviedo: Trabe, 2014.

SAYWITZ, Karen; Camparo, Lorinda. Interviewing children: a primer. In: MELTON, Gary B. et al. (Ed.). The SAGE handbook of child research. London: SAGE, 2014. p. 371-391.

SCHLEPPEGRELL, Mary J. The language of schooling: a functional linguistics perspective. Mahwah: New Jersey: Lawrence Erlbaum Associates, 2004

SHAW, Catherine; BRADY, Louca-May; DAVEY, Carey. Guidelines for research with children and young people. London: National Children's Bureau, 2011.

SIM-SIM, Inês. Desenvolvimento profissional no ensino da língua: contributos do Programa Nacional de Ensino do Português (PNEP). Lisboa: Colibri, 2011.

THE NEW LONDON GROUP. A pedagogy of multiliteracies. In: COPE, Bill; KALANTZIS, Mary (Ed.). Multiliteracies. London: Routledge, 2000. p. 19-37.

VAN OERS, Bert. Cultural-historical perspectives on play: central issues. In: BROOKER, Liz et al. (Ed.). The SAGE handbook of play and learning in early childhood education. London: SAGE, 2014. p. 56-66.

VYGOTSKY, Lev Semyonovich. El desarrollo de los procesos psicológicos superiores. Barcelona: Crítica, 1979.

VYGOTSKY, Lev Semyonovich. Pensamiento y lenguaje. Barcelona: Paidós, 1995.

WERTSCH, James V. Voices of the mind: a sociocultural approach to mediated action. Cambridge: Harvard, 1991.

WOOD, Elizabeth. The play-pedagogy interface in contemporary debates. In: BROOKER, Liz et al. (Ed.). The SAGE handbook of play and learning in early childhood education. London: SAGE, 2014. p. 145-156.

Recebido em: 18.08.2015

Aprovado em: 16.02.2016

Íris Susana Pires Pereira é professora auxiliar no Departamento de Estudos Integrados de Literacia, Didáctica e Supervisão do Instituto da Educação da Universidade do Minho. É investigadora integrada no Grupo Tecnologias, Multiliteracias e Curriculum do Centro de Investigação em Educação (CIEd) da mesma universidade. 